\title{
ARTICLE
}

\section{A role for the CCR5-CCL5 interaction in the preferential migration of HSV-2-specific effector cells to the vaginal mucosa upon nasal immunization}

\author{
Sunyi Joo ${ }^{1}$, Aldina Suwanto ${ }^{1}$, Ayuko Sato ${ }^{1}$, Rika Nakahashi-Ouchida ${ }^{1,2}$, Hiromi Mori ${ }^{1,2}$, Yohei Uchida ${ }^{1,2}$, Shintaro Sato ${ }^{1,2,3}$, \\ Yosuke Kurashima ${ }^{1,2,4,5,6}$, Yoshikazu Yuki ${ }^{1,2}$, Kohtaro Fujihashi ${ }^{1,2,7}$, Yasushi Kawaguchi ${ }^{8}$ and Hiroshi Kiyono ${ }^{1,2,5,9}$
}

Our current study focused on elucidating the role of specific chemokine-receptor interactions in antigen (Ag)-specific immune cell migration from nasal to genital mucosal tissues. This cellular migration is critical to induce effective Ag-specific immune responses against sexually transmitted genital infections. In this study, nasal immunization with live attenuated HSV- $2 \mathrm{TK}^{-}$induced the upregulation of CCR5 expression in effector immune cells, including CD4 ${ }^{+} \mathrm{T}$ cells, in Ag-priming sites and vaginal tissue. The CCR5 ligands CCL3, CCL4, and CCL5 all showed upregulated expression in vaginal tissue; in particular, CCL5 expression was highly enhanced in the stromal cells of vaginal tissue after nasal immunization. Intravaginal blockade of CCL5 by using neutralizing antibody diminished the number of HSV-2-specific effector cells in the vagina. Furthermore, loss of CCR5, a receptor for CCL5, impaired the migration of nasally primed Ag-specific effector cells from the airway to vagina. Effector cells adoptively transferred from CCR5-deficient mice failed to migrate into vaginal tissue, consequently increasing recipient mice's susceptibility to HSV-2 vaginal infection. These results indicate that the CCR5-CCL5 chemokine pathway is required for the migration and retention of nasally primed Ag-specific effector cells in vagina for providing protective immunity against HSV-2 infection.

Mucosal Immunology (2019) 12:1391-1403; https://doi.org/10.1038/s41385-019-0203-z

\section{INTRODUCTION}

Sexually transmitted diseases (STDs), such as acquired immunodeficiency syndrome, chlamydial infection, and genital herpes, remain some of the most challenging infectious diseases that currently threaten public health. ${ }^{1}$ Despite the high burden of STDs, except for vaccines against human papilloma virus, approved vaccines for STDs are unavailable. ${ }^{1,2}$ Among STDs, genital herpes caused by herpes simplex virus 2 (HSV-2) is an incurable and chronic disease that affects 500 million people worldwide. ${ }^{3}$ In recent human clinical trials, herpes subunit vaccines (e.g., targeting glycoprotein $D$ [HerpeVac]) failed to prevent genital herpes in male and female participants. ${ }^{4}$ Because HSV-2 subunit vaccine candidates have focused primarily on eliciting antibody ( $\mathrm{Ab}$ ) responses, they failed to induce potent $T$ cell-mediated immune responses at the site of infection. 2,5 Therefore, given that HSV-2 infection is specifically initiated in the genital tract, ${ }^{1,6}$ vaccination strategies that focus on inducing strong mucosal cell-mediated immunity locally may be crucial for developing a successful vaccine against HSV-2.
The mucosal immune system is a compartmentalized and interconnected system and studies of different mucosal immunization routes have shown that Ag-specific immune response are strongest at the mucosa exposed directly to the vaccine, followed by adjacent mucosal tissues. ${ }^{7}$ Notably, nasal immunization is exceptional in that it elicits substantial Ag-specific mucosal immune responses in the genital tract as well as the respiratory tract. ${ }^{7,8}$ This phenomenon is of particular interest as a possible vaccination strategy against STDs, for which a nasal vaccine has not yet been approved. ${ }^{6,9}$ Therefore studies about underlying mechanisms by which nasal vaccination induces genital immune responses are needed to provide immunological insights into successful nasal vaccine design for STDs, including HSV-2 infection.

To address these issues, HSV-2 that lacked thymidine kinase (i.e., HSV-2 $\mathrm{TK}^{-}$) was used in a murine model of genital HSV-2 infection. $\mathrm{HSV}-2 \mathrm{TK}^{-}$is a live attenuated strain of HSV-2 that replicates in vaginal keratinocytes and causes latent infection in dorsal root ganglia but does not reactivate. ${ }^{10}$ Furthermore, mice immunized with HSV-2 TK$^{-}$by either systemic or nasal routes are protected

\footnotetext{
${ }^{1}$ Division of Mucosal Immunology, Department of Microbiology and Immunology, The Institute of Medical Science, The University of Tokyo, Tokyo, Japan; ${ }^{2}$ International Research and Development Center for Mucosal Vaccines, The Institute of Medical Science, The University of Tokyo, Tokyo, Japan; ${ }^{3}$ Mucosal Vaccine Project, BIKEN Innovative Vaccine Research Alliance Laboratories, Research Institute for Microbial Diseases (RIMD), Osaka University, Osaka, Japan; ${ }^{4}$ Institute for Global Prominent Research, Chiba University, Chiba,

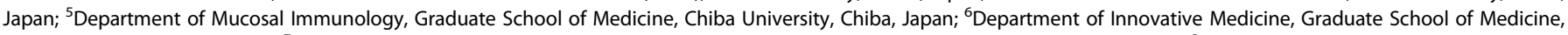
Chiba University, Chiba, Japan; ${ }^{7}$ Department of Pediatric Dentistry, The University of Alabama at Birmingham, Birmingham, AL, USA; ${ }^{8}$ Division of Viral Infection, Department of

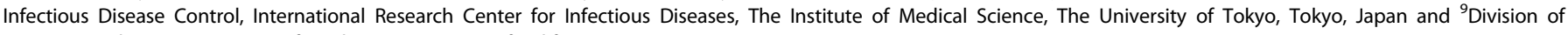
Gastroenterology, Department of Medicine, University of California, San Diego, San Diego, CA, USA

Correspondence: Hiroshi Kiyono (kiyono@ims.u-tokyo.ac.jp)

These authors contributed equally: Sunyi Joo, Aldina Suwanto
}

Received: 21 September 2018 Revised: 9 August 2019 Accepted: 25 August 2019

Published online: 24 September 2019 
1392

against subsequent challenge with wild-type (WT) HSV-2 virus. ${ }^{10,11}$ Because of these advantages, HSV-2 TK$^{-}$has been used frequently in animal vaccination models for understanding host immune responses to HSV-2 infection. ${ }^{12-15}$

Our group previously showed that nasal immunization using a live attenuated strain of HSV-2 (HSV-2 $\left.\mathrm{TK}^{-}\right)$induced Ag-specific effector-cell responses and led to the migration and retention of Ag-specific effector cells in the genital tract. ${ }^{12}$ Compared with systemic immunization, nasal immunization more effectively generated tissue-resident memory $\mathrm{T}$ cells, which are critical for vaginal protection against viral challenge. ${ }^{12,16}$ Tissue-resident memory $T$ cells are a recently identified lymphocyte lineage that is found in peripheral tissues such as the genital tract and that requires the expression of specific chemoattractants and homing receptors for T-cell recruitment and retention. ${ }^{17}$ Several lines of evidence indicate that the responses of circulatory memory T cells are not necessarily correlated with host protection against HSV-2 infection; ${ }^{12-14}$ rather, the induction and retention of Ag-specific memory $T$ cells at the local genital tissue is critical for protection against genital virus infection and is key to the design of STD vaccines. $^{12-14}$ However, the molecular-homing mechanisms underlying the effectiveness of the nasal delivery route in eliciting Ag-specific mucosal immune response at the distant vaginal mucosa and in establishing tissue-resident memory $T$ cells remain unknown.

Regarding the complex leukocyte trafficking in the mucosal immune system, T cells are imprinted to upregulate the expression of tissue-specific homing receptors, such as chemokine receptors (e.g., CCR9) and integrin (e.g., $a_{4} \beta_{7}$ ), upon activation in draining lymph nodes. ${ }^{18}$ These activated $\mathrm{T}$ cells then are recruited to specific tissues by following coordinated chemokine gradient. ${ }^{19,20}$ Chemokines are a group of small $(8-14 \mathrm{kDa})$ proteins that bind to 7-transmembrane G protein-coupled receptors and, to date, 50 mammalian chemokines have been identified, which signal through 20 distinct receptors. ${ }^{21}$ In addition, several chemokine receptors for homing to specific surface tissues of skin and mucosa have been identified. For example, memory lymphocytes programmed to migrate into the skin express chemokine receptor CCR4, CCR10, or both receptors, which interact with the dermisassociated chemokine ligands CCL17 and CCL27, respectively. ${ }^{22,23}$ Memory lymphocytes that home to the gut specifically express CCR9, which binds to CCL25 expressed on intestinal epithelial cells. ${ }^{24,25}$ However, the chemokine receptors and their ligands that direct lymphocytes to the lower genital tract after nasal immunization remain largely uncharacterized, despite the fact that nasal immunization is an effective delivery route for the induction of Ag-specific immune response in the distant reproductive tissue. ${ }^{12,26}$

Here we used a murine HSV-2 $\mathrm{TK}^{-}$nasal vaccination model to investigate the involvement of interaction between chemokines and chemokine receptors in the homing of nasally primed $\mathrm{Ag}$ specific effector cells to the vaginal mucosa.

\section{RESULTS}

Nasally primed Ag-specific effector cells migrate from the nasal mucosa to the vaginal mucosa in a signaling pathway sensitive to pertussis toxin (PTx)

To test whether the interaction between a chemokine and its receptor mediates migration of nasally primed Ag-specific effector cells, we first examined whether a signaling pathway sensitive to PTx is involved in the migration mechanism that follows nasal immunization with $\mathrm{HSV}-2 \mathrm{TK}^{-}$. PTx inhibits Gai signaling downstream of many chemokine receptors that are involved in lymphocyte trafficking. ${ }^{27}$ WT C57BL/6 mice nasally immunized with HSV-2 $\mathrm{TK}^{-}$were treated with PTx intravaginally for 4 consecutive days (days 3 through 6 after HSV-2 TK ${ }^{-}$immunization); the absolute numbers of HSV-2-specific IFN- $\gamma$-secreting cells
(ISCs) in vaginas at day 7 were measured by using ELISPOT assays (Fig. 1a). The numbers of Ag-specific IFN- $\gamma$-producing effector cells were significantly decreased in the vaginal tissues of the mice treated with PTx after nasal immunization when compared with those from nontreated nasal immunization group (Fig. 1b). In contrast, PTx treatment did not alter the number of Ag-specific effector cells in spleen (Fig. 1C). These results show that the migration of nasally primed IFN- $\gamma$-producing effector cells depends on a PTx-sensitive signaling pathway. This finding thus suggests that chemokine-receptor signaling in local vaginal tissues is required for the migration of Ag-specific effector cells from nasal mucosa to vagina.

\section{CCR5 mediates the migration of nasally primed effector cells to} the vaginal mucosa

To identify specific chemokine receptors that mediate the migration pathway from nasal to vaginal mucosa, we used reverse transcription (RT)-PCR analysis to examine chemokine receptorspecific mRNA expression in the cervical lymph nodes (CLNs), which are the priming site for nasal immunization, ${ }^{7}$ at 1 week after nasal immunization with HSV-2 $\mathrm{TK}^{-}$. Among the CXC (C-X-C motif), CX3C (C-XXX-C motif), and CC (C-C motif) subgroups of chemokine receptors, ${ }^{21}$ our results showed that the mRNA levels of CXCR3, CXCR4, and CCR5 were significantly upregulated in CLNs after nasal immunization with HSV-2 $\mathrm{TK}^{-}$(Fig. 2a).

The increase in the expression of CXCR3, CXCR4, and CCR5 in lymphocytes of Ag-priming sites suggests the possible involvement of those chemokine receptors in the migration of nasally primed Ag-specific effector cells. Because a previous study showed that $\mathrm{CD}^{+} \mathrm{T}$ cells are critical for the induction of protective immunity after nasal immunization with $\mathrm{HSV}-2 \mathrm{TK}^{-1}, 12$ we used flow cytometry to assess the expression of CXCR3, CXCR4, and CCR5 by $\mathrm{CD}^{+}{ }^{+} \mathrm{T}$ cells from spleen, CLNs, and vaginal tissue of mice at 1 week after systemic (i.p.) and nasal immunization with HSV-2 $\mathrm{TK}^{-}$and in nonimmunized controls (i.e., received PBS only nasally). The analysis showed that the frequency of $\mathrm{CCR} 5^{+} \mathrm{CD} 4^{+}$ $T$ cells from CLNs was upregulated in mice given nasal HSV-2 $\mathrm{TK}^{-}$ when compared with nonimmune and systemically immunized groups (Fig. 2b). In spleen and vaginal tissue, the frequency and absolute number of $\mathrm{CCR}^{+} \mathrm{CD}^{+}{ }^{+}$T cells were increased in both the nasally and systemically immunized groups when compared with nonimmunized mice (Fig. 2b). In addition, $\mathrm{CD}^{+}{ }^{+}$cells from relevant tissues (spleen, CLNs, and vagina) exhibited higher expression of CXCR3 after nasal immunization compared with nonimmunized controls (Supplementary Fig. S1a); however, CXCR4 expression on CD4 ${ }^{+} \mathrm{T}$ cells was comparable between naive and nasally immunized mice (Supplementary Fig. S1b). These findings suggest that the expression of both CXCR3 and CCR5 was induced in $\mathrm{CD}^{+} \mathrm{T}$ cells of spleen, CLNs, and vaginal tissues through nasal immunization with $\mathrm{HSV}-2 \mathrm{TK}^{-}$.

The increase in the numbers of $\mathrm{CD}^{+}{ }^{+} \mathrm{T}$ cells expressing CCR5 and CXCR3 after nasal immunization with HSV-2 $\mathrm{TK}^{-}$suggested that those receptors might be essential for the migration of nasally primed effector cells from nasal to vaginal mucosa. We therefore examined the number of migrated Ag-specific effector cells in the female genital tract after nasal immunization of mice deficient in either CCR5 or CXCR3 when compared with littermate-control mice. ELISPOT assays showed that, at 1 week after nasal immunization, CCR5-deficient $\left(\mathrm{CCR}^{-1-}\right)$ mice had significantly fewer Ag-specific IFN- $\gamma$ secreting cells in vaginal tissue, but not in spleen when compared with their littermate controls $\left(\mathrm{CCR}^{+/-}\right)$ (Fig. 2c). In contrast, the number of Ag-specific IFN- $\gamma$ secreting cells in spleen and vaginal tissue did not differ significantly between CXCR3-deficient (CXCR3 ${ }^{-1-}$ ) mice and their littermate controls after nasal immunization with HSV-2 TK ${ }^{-}$(Supplementary Fig. S2a, b). Taken together, these results suggest that the chemokine receptor CCR5 may be needed for the migration of nasally primed effector cells from the nasal mucosa to the vaginal 
a

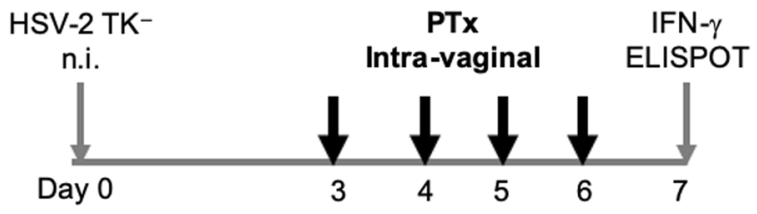

b

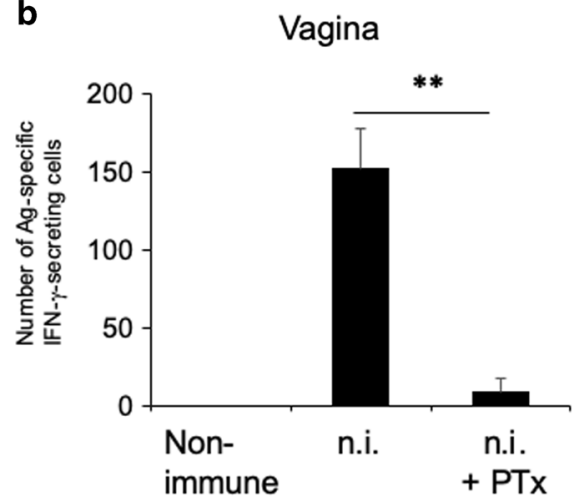

C

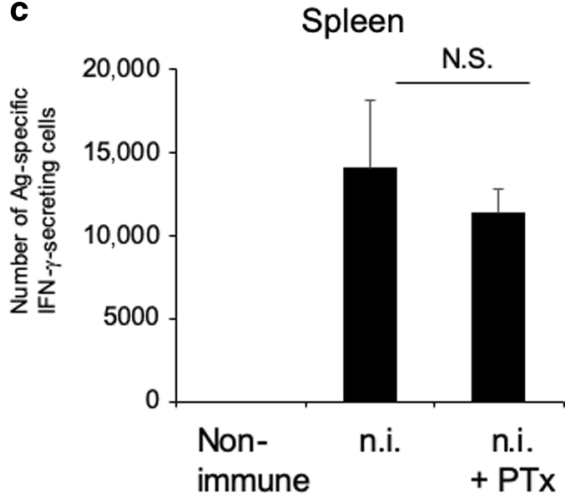

Fig. 1 Intravaginal PTx treatment diminishes the number of HSV-2-specific IFN- $\gamma$-secreting cells in vaginal tissue after nasal immunization (n.i.). Each group of three mice was immunized with a single nasal dose of $10^{5}$ PFU of HSV-2 TK ${ }^{-}$or PBS (nonimmunized group). For the PTx treatment, PTx $(0.5 \mu \mathrm{g})$ was administered intravaginally for 4 consecutive days (days 3 through 6$)$ after nasal immunization. On day 7 , whole cells prepared from the vaginal tissues or spleens of the three mice in each group were pooled and stimulated by coincubation for $72 \mathrm{~h}$ in vitro with irradiated syngeneic splenocytes (as antigen-presenting cells) and heat-inactivated virus antigens, as shown in a. The absolute numbers of IFN- $\gamma$-secreting cells in the $\mathbf{b}$ vaginal tissues and $\mathbf{c}$ splenic tissue at 1 week after immunization were calculated by using ELISPOT assays. Values are means \pm 1 SD ( $n=3$ per group). Data are representative of two independent experiments. ${ }^{* *} P<0.01$ versus nasally immunized (n.i.) mice

mucosa after nasal immunization of mice with $\mathrm{HSV}-2 \mathrm{TK}^{-}$. Given that our previous study revealed markedly increased numbers of $\mathrm{CD}^{+}{ }^{+} \mathrm{T}$ cells in the vagina of mice given nasal $\mathrm{HSV}-2 \mathrm{TK}^{-}$ after WT viral challenge, we assessed whether recent immigrant $\mathrm{CD}^{+} \mathrm{T}$ cells are retained as tissue-resident memory $\mathrm{T}$ cells in vagina after nasal immunization with $\mathrm{HSV}-2 \mathrm{TK}^{-}$. Tissue-resident memory CD4 ${ }^{+}$T cells $\left(\mathrm{CD} 4^{+}, \mathrm{CD} 44^{\text {hi }}, \mathrm{CD} 4 \mathrm{a}^{+}, \mathrm{CD} 69^{+}\right.$, and $\left.\mathrm{CD} 6 \mathrm{~L}^{-}\right)$ in vagina were more numerous at 7 days after nasal vaccination when compared with those of nonimmunized mice (Fig. 2d) (Supplementary Fig. S3). The vaginal cell population was further increased in number at 21 days after the nasal vaccination (Fig. 2d). We also noticed that these vaginal-resident memory $\mathrm{CD}^{+}{ }^{+} \mathrm{T}$ cells did not the express CCR5 molecules (data not shown). These results suggest that the majority of recently immigrated $\mathrm{CCR}^{+} \mathrm{CD}^{+} \mathrm{T}$ cells might become vaginal-resident memory $\mathrm{CD} 4^{+}$ $T$ cells through loss of CCR5 expression.

Expression of chemokine ligand CCL5 is upregulated in vaginal tissue after nasal immunization with HSV-2 TK

To determine whether CCR5 ligands are involved in the migration of nasally primed effector cells to the vaginal mucosa, we performed RT-quantitative PCR (qPCR) analyses of CCL3, CCL4, and CCL5, which are ligands for CCR5. ${ }^{21}$ Compared with those in nonimmune mice, the levels of CCL3-, CCL4-, and CCL5-specific mRNA expression were all increased in nasally immunized mice. In particular, CCL5 expression in both nasally and intraperitoneally (i.p.) immunized mice was significantly higher than that of nonimmunized controls (Fig. 3a).

We then examined the localization and cellular source of CCL5 within vaginal tissue after immunization with $\mathrm{HSV}-2 \mathrm{TK}^{-}$, because CCL5 expression was the most strikingly increased among the three CCR5-related chemokines (Fig. 3a). Immunohistochemical analysis showed that the fluorescence intensity of CCL5 was higher in mice given nasal or i.p. HSV-2 $\mathrm{TK}^{-}$than in nonimmunized mice (i.e., nasally administered PBS only) (Fig. 3b). Analysis of the co-localization of staining for CCL5 and CD45, a pan- hematopoietic cell surface molecule, ${ }^{28}$ revealed that CCL5 expression was significantly enhanced in both $\mathrm{CD} 45^{+}$hematopoietic cells and $\mathrm{CD}^{-} 5^{-}$stromal cells in the vaginal tissue of mice immunized with HSV-2 $\mathrm{TK}^{-}$through either the nasal or i.p. route when compared with that expression in nonimmunized mice (Fig. 3b). Consistent with these findings, RT-qPCR analysis revealed that the levels of CCL5-specific mRNA in both CD45 ${ }^{-}$- and $C D 45^{+}$enriched cells isolated from vaginal tissue were significantly and highly upregulated in response to nasal immunization with HSV-2 $\mathrm{TK}^{-}$when compared with those from nonimmunized mice (Fig. 3c).

To confirm whether stromal cells produce CCL5 after immunization with $\mathrm{HSV}-2 \mathrm{TK}^{-}$, we used col-GFP transgenic mice, which express green fluorescent protein (GFP) under the control of the collagen a1 (I) promoter-enhancer. ${ }^{29}$ Nasally immunized col-GFP mice showed co-localization of collagen and CCL5 in the submucosal area of vaginal tissue (Fig. $3 d$ ). We then purified the collagen-producing stromal cells from the vaginal tissues of col-GFP mice given nasal HSV-2 $\mathrm{TK}^{-}$or PBS and found that CCL5 expression in the $\mathrm{CD}^{-} 5^{-} \mathrm{GFP}^{+}$cell population was significantly increased after nasal immunization (Fig. 3e). These results suggest that vaginal type I collagenproducing stromal cells from mice nasally immunized with HSV$2 \mathrm{TK}^{-}$express higher levels of CCL5 than those from nonimmunized mice.

The chemokine CCL5 is required for the migration of Ag-specific effector cells to vaginal tissue after nasal immunization with HSV-2 TK-

We next addressed whether these chemokine ligands are required for the migration of Ag-specific effector cells to the vagina after nasal immunization. Mice given nasal HSV-2 $\mathrm{TK}^{-}$were intravaginally treated with neutralizing mAbs against CCL3, CCL4, CCL5, or $m A b$ cocktail (i.e., a mixture of anti-CCL3, anti-CCL4, and anti-CCL5 mAbs). Blocking of CCL5 by using each specific mAb and the $\mathrm{mAb}$ cocktail significantly reduced the number of Ag-specific 


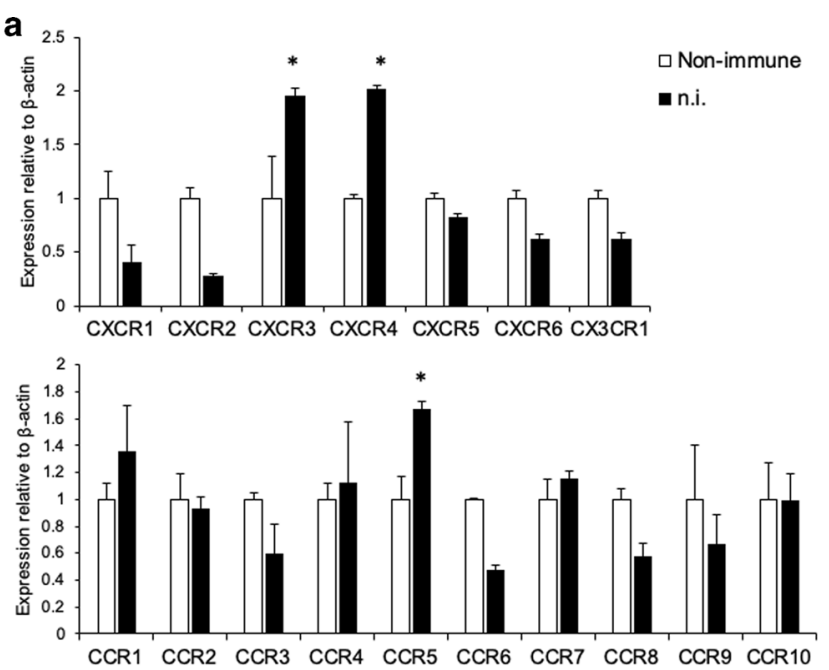

b
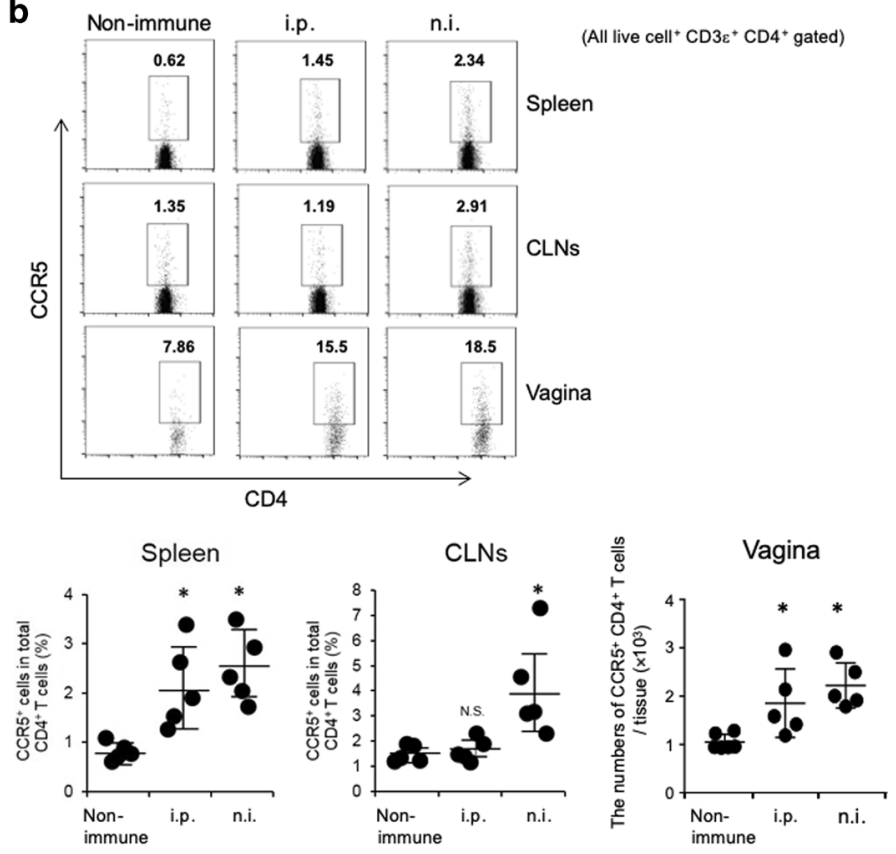

C
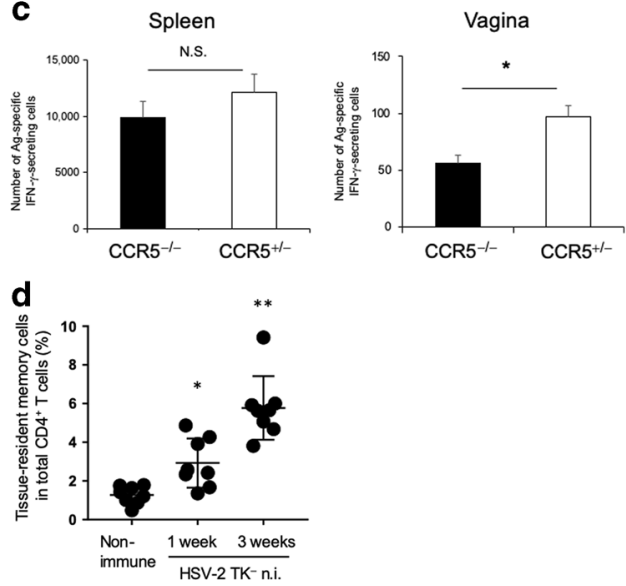

IFN- $\gamma$-producing effectors cells in vaginal tissue, although the quantity of effector cells in the spleens of anti-CCL5 mAb- and $\mathrm{mAb}$ cocktail-treated mice was similar to that of isotype mAbtreated mice (Fig. 4a). However, the mice treated with anti-CCL3 or
anti-CCL4 mAb did not show any significant changes in the numbers of Ag-specific IFN- $\gamma$-producing effectors cells in either vaginal or spleen tissue compared with those given the isotype control mAb (Fig. 4a). 
Fig. 2 CCR5 expression is upregulated in relevant tissues after nasal immunization (n.i.) with HSV-2 $\mathrm{TK}^{-}$and is necessary for the migration of Ag-specific effector cells from nasal mucosa to vagina tissue. Mice received a single nasal or intraperitoneal (i.p.) inoculation of PBS (nonimmune group) or $10^{5} \mathrm{PFU}$ of live HSV-2 $\mathrm{TK}^{-}$; all samples were harvested 1 week after immunization. a RT-qPCR analysis of mRNA expression of chemokine receptors in cervical lymph nodes (CLNs) of nasally immunized mice. The mRNA expression level was normalized to that of $\beta$-actin, and data are expressed relative to the value for nonimmunized controls. Values are means \pm 1 SD ( $n=3$ or 4 mice per group). ${ }^{*} P<0.05$ versus nonimmunized mice. Data are representative of two independent experiments. $\mathbf{b}$ Mononuclear cells were isolated from the spleen, CLNs, and vaginal tissue of mice immunized by using a single nasal or intraperitoneal (i.p.) dose comprising $10^{5}$ PFU of live HSV-2 TK for analysis of cell surface or intracellular CCR5 expression by CD4 ${ }^{+} \mathrm{T}$ cells by flow cytometry. Samples were harvested 1 week after immunization. Numbers in plots represent the percentage among total $\mathrm{CD}^{+}{ }^{\top} \mathrm{T}$ cells. Data are representative of three independent experiments. Percentages of CCR5 ${ }^{+}$cells among total $\mathrm{CD}^{+}{ }^{+} \mathrm{T}$ cells (spleen and CLNs) or the absolute numbers of CCR5 ${ }^{+}, \mathrm{CD}^{+}{ }^{+} \mathrm{T}_{\text {cells in }}$ vagina are shown. ${ }^{*} P<0.05$ versus nonimmunized mice (nasal PBS) group ( $n=5$ mice per group from pooled experiments). $c$ Female CCR5 ${ }^{-/-}$ mice and their littermate controls were immunized with a single nasal dose of $10^{5}$ PFU of HSV-2 TK ${ }^{-}$. The numbers of HSV-2-specific IFN- $\gamma$ producing effector cells at day 7 after immunization in pooled samples of spleen and vaginal tissue were measured by ELISPOT assay as described in the legend for Fig. 1. Values are means \pm 1 SD. ${ }^{*} P<0.05$ versus $C C R 5^{-1-}$ mice group $(n=5$ or 6 mice per group from pooled experiments); \pm heterozygous littermates (controls); N.S. not significant. d Female mice were given a single dose of HSV-2 TK ${ }^{-}\left(10^{5}\right.$ PFU/ mouse) or PBS (nonimmunized control). Mononuclear cells were isolated from the vaginal tissue 1 and 3 weeks after the immunization and stained for tissue-resident memory CD4 ${ }^{+}$T cells (CD4 ${ }^{+}, \mathrm{CD} 44^{\text {high }}, \mathrm{CD} 49 \mathrm{a}^{+}$, and $\left.\mathrm{CD} 6 \mathrm{~L}^{-}\right)$. The percentage of tissue-resident CD4 ${ }^{+} \mathrm{T}_{\text {cells }}$ in the vaginal tissue was shown. ${ }^{*} P<0.05,{ }^{* *} P<0.01$ versus nonimmunized mice (nasal PBS) group ( $n=5$ mice per group from pooled experiments)

To determine whether topical CCL5 treatment of vaginal mucosa is sufficient to recruit Ag-specific effector cells, we adopted a "prime-and-pull" strategy, as previously described. ${ }^{13}$ Mice subcutaneously immunized with $\mathrm{HSV}-2 \mathrm{TK}^{-}$each received a single dose of recombinant CCL5 into the vaginal cavity at 6 days after immunization. On day 7 , subcutaneously immunized mice had fewer Ag-specific IFN- $\gamma$-producing cells in the vagina than did nasally immunized mice, but splenic tissues showed no significant change in cell numbers (Fig. 4b). This population of cells in the vagina was significantly increased in the mice that received the chemokine pull (i.e., subcutaneous immunization plus CCL5) compared with subcutaneous immunization alone (Fig. 4b). Therefore, these data show that the chemokine ligand CCL5 is capable of recruiting systemically primed effector $\mathrm{CCR}^{+}$cells into vaginal tissue.

Taken together, these findings demonstrate that the chemokine CCL5-but not CCL3 or CCL4-is essential for the migration of HSV-2-specific IFN- $\gamma$-secreting effector cells into vaginal tissue after nasal immunization with HSV-2 $\mathrm{TK}^{-}$.

Effector cells generated in nasally immunized $\mathrm{CCR}^{-1-}$ mice do not protect against WT virus challenge

To examine whether the $\mathrm{CCR}^{+}$effector cells induced by nasal immunization are capable of migrating to the vagina and providing protective immunity against intravaginal WT HSV-2 virus challenge, mice were adoptively transferred with whole cells from the CLNs of WT or CCR5 ${ }^{-1-}$ mice given nasal HSV-2 $\mathrm{TK}^{-}$; recipient mice were then challenged intravaginally with WT HSV-2 virus. Consistent with the results from our previous study, ${ }^{12}$ mice adoptively transferred with CLN cells from the nasally immunized WT mice survived without severe vaginal inflammation after intravaginal challenge with $5 \times 10^{4}$ plaqueforming units (PFU) $\left(80 \mathrm{LD}_{50}\right)$ of WT HSV-2 (Fig. $\left.5 \mathrm{a}-\mathrm{c}\right)$. In contrast, mice that received CLN cells from nasally immunized CCR5 ${ }^{-1-}$ donors had impaired protective immune responses, leading to the development of high-viral titers in vaginal washes, purulent genital lesions, and hindlimb paralysis after virus challenge (Fig. $5 a-c)$. To further highlight the differential role of CCR5 in the protection by CLN cell transfer between $\mathrm{CCR}^{-/-}$and WT mice, IFN- $\gamma$ production by $\mathrm{CD}^{+}{ }^{+} \mathrm{T}$ cells from the CLNs of these mice was assessed. Intracellular cytokine analyses revealed that $\mathrm{CD}^{+} \mathrm{T}$ cells from both $\mathrm{CCR}^{-/-}$and WT mice contained essentially the same frequency of IFN- $\gamma$-producing cells (Fig. $5 \mathrm{~d}$ ). These results suggest that adoptively transferred effector cells generated in nasally immunized $\mathrm{CCR}^{-1-}$ mice were unable to migrate into the vagina of naive mice and thus did not provide protective immunity against intravaginal challenge with WT HSV-2 virus.
In addition, $\mathrm{CCR}^{-1-}$ mice were nasally immunized with HSV-2 $\mathrm{TK}^{-}$and then challenged intravaginally with WT HSV-2 virus. Although all nasally immunized WT and $C C R 5^{-1-}$ mice survived after challenge with WT virus, the immunized $\mathrm{CCR}^{-1-}$ mice developed vaginal erythema during days 5 through 7 after infection (Supplementary Fig. S4a, b). Viral titers in vaginal washes of immunized $\mathrm{CCR}^{-/-}$mice were higher than those from the immunized WT mice, especially on day 1 after infection (Supplementary Fig. S4c). These results suggest that the CCR5-CCL5 chemokine axis is important for nasal induction of IFN- $\gamma$-producing effector-cell responses in the reproductive tissues to achieve early clearance of HSV-2 infection.

CCL5 production after nasal immunization depends on migrated IFN- $\gamma$-producing cells in vaginal tissue

To investigate the mechanism by which CCL5 is produced in vaginal tissue after nasal immunization, we tested whether this response occurred after migration of nasally primed effector cells from Ag-priming sites. During nasal immunization with $\mathrm{HSV}-2 \mathrm{TK}^{-}$, mice were treated with FTY 720, an analog of sphingosine-1phosphate, which inhibits lymphocyte emigration from the secondary lymphoid organs. ${ }^{30}$ Consistent with previous findings, ${ }^{31}$ FTY 720 treatment dramatically diminished HSV-2-specific IFN- $\gamma$ producing cells in both spleen and vaginal tissue compared with those in PBS (mock)-treated nasally immunized controls (Fig. 6a). In support of this finding, the vast majority of CCR5 ${ }^{+} \mathrm{CD} 4^{+} \mathrm{T}$ cells in CLNs induced by nasal HSV-2 TK ${ }^{-}$expressed sphingosine-1phosphate receptor $1\left(\mathrm{~S}_{\mathrm{P}}\right)$ (Fig. 6b). In addition, $\mathrm{qPCR}$ analysis revealed that FTY treatment greatly decreased CCL5 production in vaginal tissue after nasal immunization (Fig. $6 \mathrm{c}$ ), suggesting that migrated cells from nasal-associated lymphoid tissue are required for CCL5 induction in vaginal tissue.

We next focused on the effect of IFN- $\gamma$ on CCL5 production, because IFN- $\gamma$, which is secreted mainly by tissue-resident $\mathrm{CD}^{+}$ $\mathrm{T}$ cells, is a key cytokine for vaginal protection against HSV-2 challenge. $^{32,33}$ To examine whether IFN- $\gamma$ is essential for the production of CCL5 in vaginal tissue, we treated nasally immunized mice with neutralizing Ab specific for IFN- $\gamma$ or an isotype-matched $\mathrm{Ab}$. The induction of CCL5 in vaginal tissue was significantly attenuated in the mice treated with IFN- $\gamma \mathrm{Ab}$ compared with that in control mice (Fig. 6d). Furthermore, when vaginal stromal cells were cultured with recombinant IFN- $\gamma(10 \mu \mathrm{g} /$ $\mathrm{ml}$ ) for 3 days, increased levels of CCL5-specific mRNA expression were noted (Supplementary Fig. S5). Collectively, these data suggest that CCL5 expression in vaginal tissue after nasal immunization with $\mathrm{HSV}-2 \mathrm{TK}^{-}$is greatly dependent on IFN- $\gamma^{-}$ producing cells that have migrated from secondary lymphoid organs to vaginal tissue. 
$\mathrm{S}$ Joo et al.

a

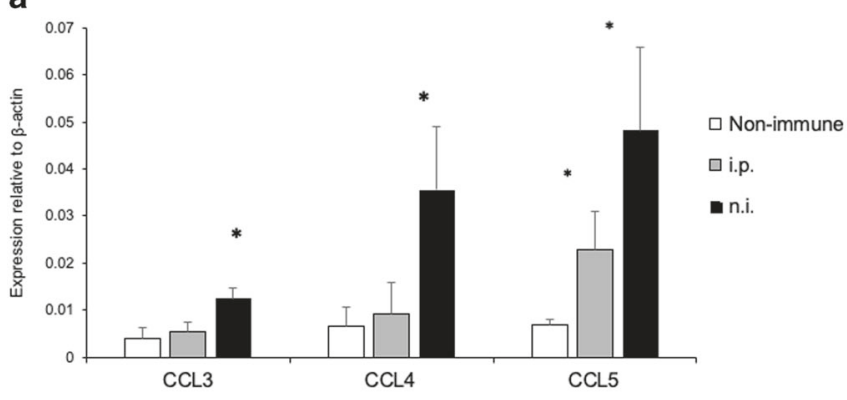

b
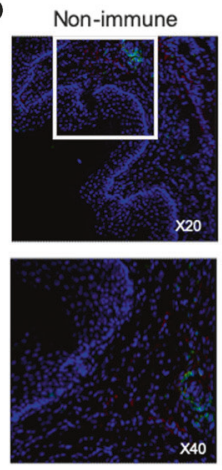

i.p.
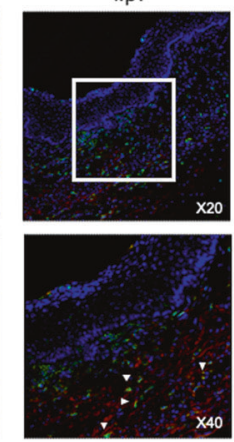

n.i.

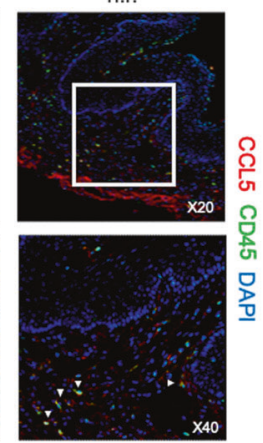

d Non-immune
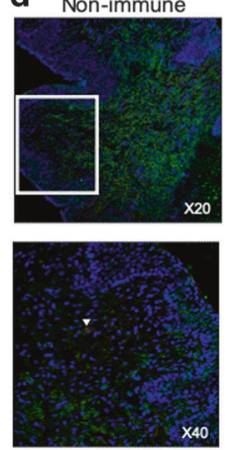

e
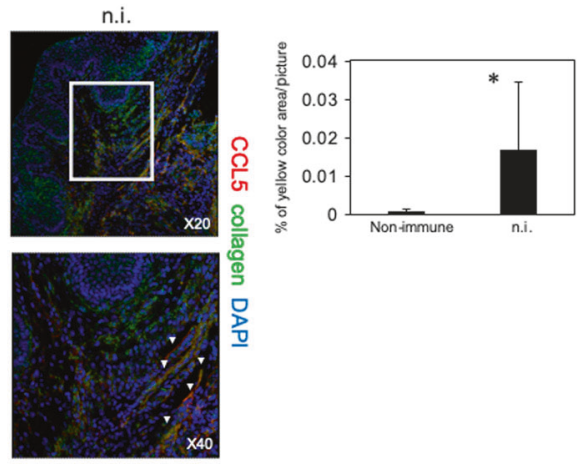
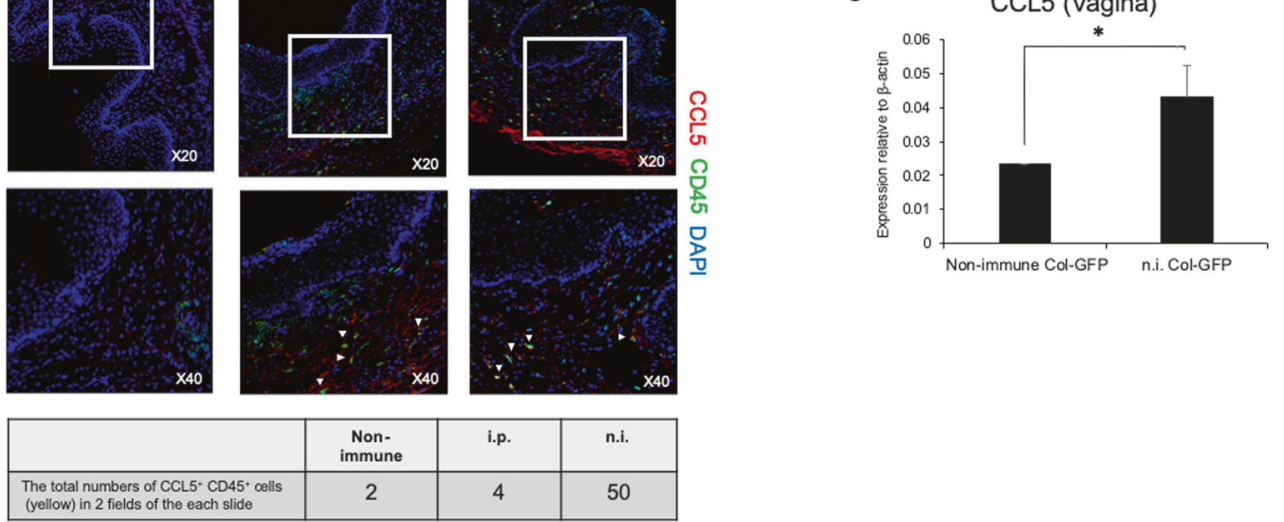

C

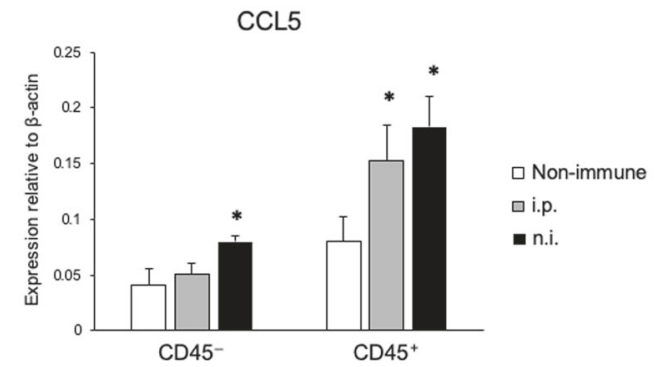

Fig. 3 Chemokine ligand expression in vaginal tissue. WT female C57BL/6 mice were immunized with a single nasal (n.i.) or intraperitoneal (i.p.) dose comprising $10^{5}$ PFU of live attenuated HSV-2 TK ${ }^{-}$. Vaginal tissue samples were harvested at 1 week after immunization. a RT-qPCR analysis of CCL3, CCL4, and CCL5 expression in vaginal tissues. Chemokine mRNA expression levels were normalized to that of $\beta$-actin. Values are means \pm 1 SD ( $n=3$ or 4 mice per group). ${ }^{*} P<0.05$ versus nonimmunized mice (nasal PBS) group. Data are representative of two independent experiments. b CCL5 expression in frozen sections of vaginal tissue was evaluated by using immunofluorescence assays. Tissue sections were prepared and stained with anti-CCL5 (red), anti-CD45 Ab (green), and DAPI (4', 6-diamidino-2-phenylindole; blue). Arrows indicate co-localization of CCL5 and CD45. Data are representative of two independent experiments $(n=3$ mice per group). The merged-color (yellow) cells in two random fields of the stained image were counted; the total numbers of $\mathrm{CD}_{4} 5^{+} \mathrm{CCL} 5^{+}$cells are presented in a table. c CCL5 expression in vaginal tissue after intraperitoneal (i.p.) and nasal immunization (n.i.) of mice with HSV-2 TK-. At 7 days after the immunization, $\mathrm{CD}_{4} 5^{-}$and $\mathrm{CD} 45^{+}$cells from vaginal tissues were enriched by magnetic activated cell sorting. The levels of CCL5-specific mRNA expression were assessed by RT-qPCR analysis and normalized to that of $\beta$-actin. Values are given as means \pm 1 SD $(n=3$ or 4 mice per group). ${ }^{*} P<0.05$ versus nonimmunized (nasal PBS) mice. Data are representative of two independent experiments. d, e Col-GFP transgenic mice were immunized with a single nasal dose comprising $10^{5}$ PFU of live HSV-2 $\mathrm{TK}^{-}$(or PBS, nonimmune controls). Vaginal tissue samples were harvested at 1 week after immunization. d CCL5 expression in frozen sections of vaginal tissue from each mice group was detected by using immunofluorescence assays. Tissue sections were prepared and stained with anti-CCL5 (red) and DAPI (4', 6-diamidino-2-phenylindole; blue). GFP (green) cells indicate type I collagen-producing cells. Arrows indicate cells where co-localization of collagen-GFP with CCL5 occurs. Data are representative of two independent experiments ( $n=2$ or 3 mice per group). The merged-color (yellow) proportion of randomly selected field of stained image was quantified by using ImageJ software (National Institutes of Health, Bethesda, MD). Values are given as means $\pm 1 \mathrm{SD}$ ( $n=3$ fields). ${ }^{*} P<0.05$ versus nonimmunized (nasal PBS) mice. e RT-qPCR analysis of CCL5 expression in $\mathrm{CD}^{-} 5^{-} \mathrm{GFP}{ }^{+}$cells from vaginal tissues of col-GFP transgenic mice after nasal immunization. Live CD45 ${ }^{-} \mathrm{GFP}^{+}$cells were sorted by flow cytometry. The CCL5 mRNA expression level was normalized to that of $\beta$-actin. Values are means \pm 1 SD ( $n=3$ or 4 mice per group). ${ }^{*} P<0.05$ versus nonimmunized colGFP transgenic mice. Samples were pooled from three independent experiments

\section{DISCUSSION}

Infection of the female genital tract can cause serious morbidities and mortalities, including reproductive disability, pelvic inflammatory disease, and cancer as well as adverse fetal effects. ${ }^{34}$
However, protective vaccination of the female reproductive tract has been difficult to achieve, because the vaccination strategies and mechanisms necessary to induce an effective local immune response are not completely understood. ${ }^{6,34}$ In this regard, nasal 
a

HSV-2 TK-

n.i.

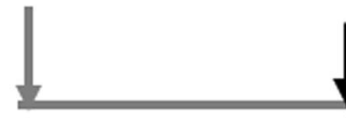

Day 0
Neutralizing mAb
Intra-vaginal
IFN- $\gamma$

ELISPOT

\section{Spleen}
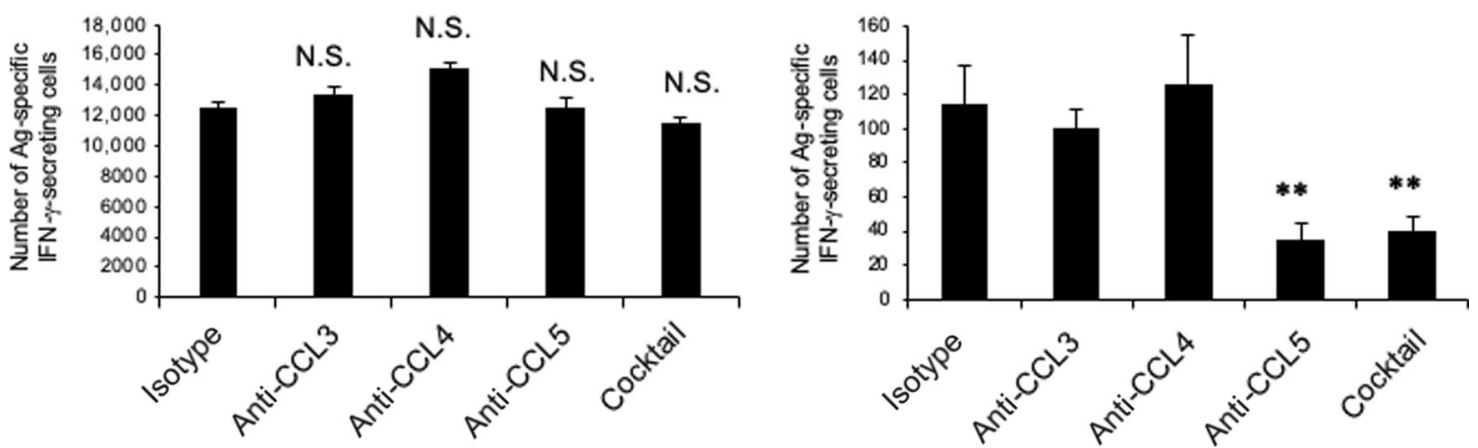

b

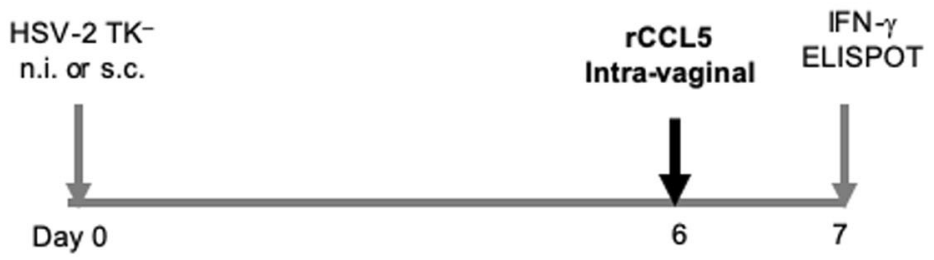

\section{Spleen}

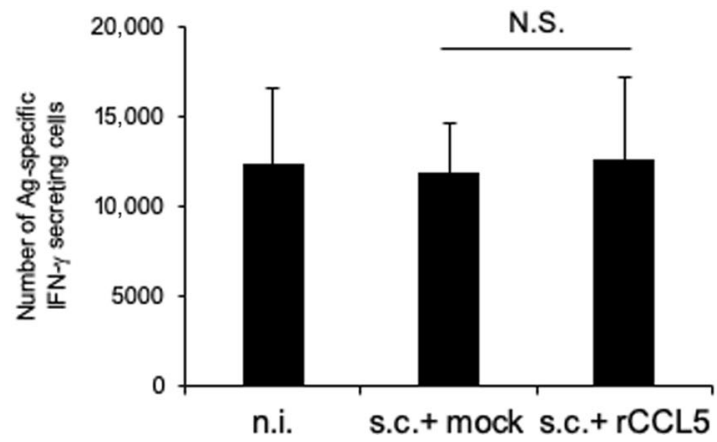

Vagina

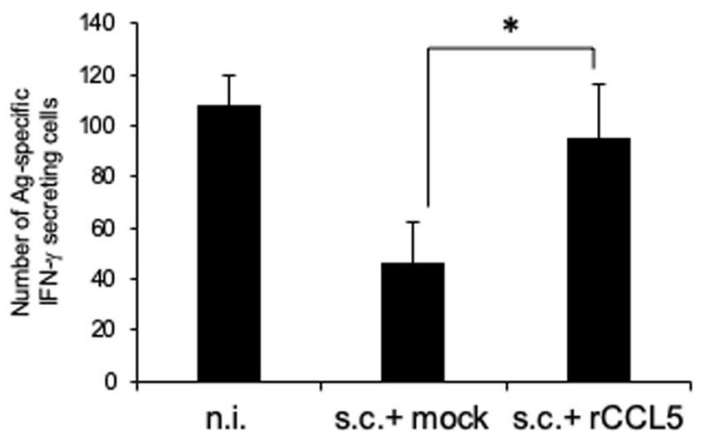

Fig. 4 Antibody blocking of CCL5 in the vagina impairs the migration of nasally primed Ag-specific effector cells to the vaginal mucosa. a Female C57BL/6 mice nasally immunized (n.i.) with HSV-2 $\mathrm{TK}^{-}$(on day 0 ) were treated intravaginally with isotype control lgG, anti-CCL3, antiCCL4, anti-CCL5 mAb, or a mAb cocktail (mixture of anti-CCL3, anti-CCL4, and anti-CCL5 mAbs) for 4 consecutive days (days 3 through 6). On day 7 , whole cells prepared from the vaginal tissues or spleens of three mice in each group were pooled and the numbers of HSV-2-specific IFN- $\gamma$-producing effector cells were measured by ELISPOT assay as described in the legend for Fig. 1. The results are representative of two independent experiments ( $n=3$ or 4 per group). The error bars indicate the standard errors (SE) for the three wells in the ELISPOT assay. ${ }^{*} P<$ 0.05 versus isotype control group. N.S. not significant. b Female mice were immunized subcutaneously (s.c.) or nasally with HSV-2 TK ${ }^{-}$on day 0 . Six days after immunization, subcutaneously immunized mice were treated intravaginally with either the chemokine CCL5 or PBS (mock); on day 7 , the absolute numbers of IFN- $\gamma$-secreting cells in the spleen and vaginal tissues were calculated by using ELISPOT assays. The data are representative of three independent experiments. Values are means \pm 1 SD ( $n=4$ mice per group). ${ }^{*} P<0.05$

immunization successfully induces effective $T$ - and B-cell responses in female genital mucosa. ${ }^{1,7,35}$ This phenomenon supports the attractive possibility that nasal vaccination might be a promising strategy for establishing protective immunity against STDs.

Using a model of genital HSV-2 infection in mice ${ }^{32}$ and vaccination with a live attenuated HSV-2 (HSV-2 $\left.\mathrm{TK}^{-}\right){ }^{10}$ our group previously showed that nasally primed HSV-2-specific effector cells migrated into the distant vaginal mucosa and subsequently protected mice from genital HSV-2 infection. ${ }^{12}$ Compared with systemic immunization, which yielded fewer effector cells in the vaginal mucosa, nasal immunization with $\mathrm{HSV}-2 \mathrm{TK}^{-}$generated numerous Ag-specific IFN- $\gamma$-secreting effector cells in the genital tract. ${ }^{12}$ In the current study, we further examined the mechanisms by which nasally primed Ag-specific effector cells migrate to the vaginal mucosa as well as the involvement of signaling due to the 
a

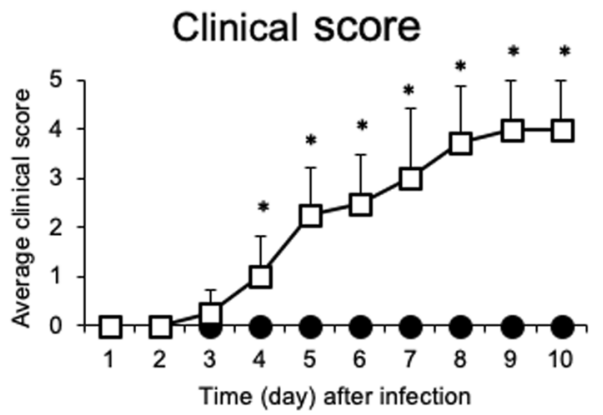

C

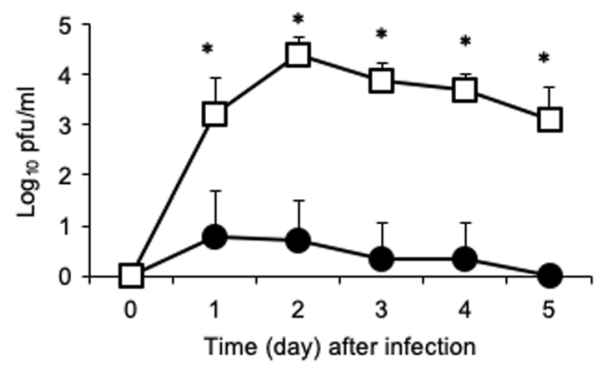

b

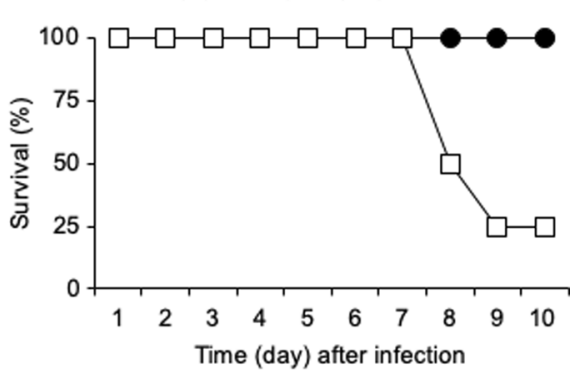

Survival rate

Time (day) after infection

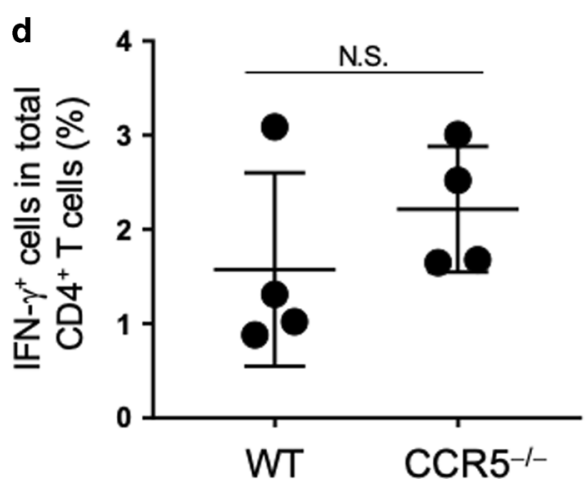

Fig. 5 Impaired viral clearance of adoptively transferred CCR5 ${ }^{-1-}$ lymphocytes. Whole cells $\left(10^{7}\right.$ cells) isolated from the CLNs of WT or CCR5 ${ }^{-1-}$ mice nasally immunized (n.i.) with HSV-2 $\mathrm{TK}^{-}$were adoptively transferred into naive $\mathrm{C} 57 \mathrm{BL} / 6$ mice. The recipient mice were then challenged intravaginally with WT HSV-2 at $5 \times 10^{4}$ PFU $\left(80 \mathrm{LD}_{50}\right) 4$ days after the cell transfer. Survival rates $(\mathbf{a})$, genital pathology scores $(\mathbf{b})$, and viral titers in vaginal washes (c) after intravaginal HSV-2 challenge. b Disease severity was scored as follows: 0 , no signs; 1 , slight genital erythema and edema; 2, moderate genital inflammation; 3, purulent genital lesions; 4 , hindlimb paralysis; and 5, moribund. d WT and CCR5 ${ }^{-1-}$ female mice received a single nasal inoculation of PBS as nonimmunized control or $10^{5} \mathrm{PFU}$ of live HSV-2 TK ${ }^{-}$. Seven days after immunization, mononuclear cells isolated from CLNs were cultured in the presence of $100 \mathrm{ng} / \mathrm{ml}$ of PMA and $1 \mathrm{ng} / \mathrm{ml}$ of ionomycin for $6 \mathrm{~h}$ and stained for surface CD4 and intracellular IFN- $\gamma$ expression. The results are representative of two separate experiments. ${ }^{*} P<0.05$, ${ }^{* *} P<0.01$. Values are means \pm 1 SD $(n=4$ mice per group). N.S. not significant

interaction between chemokines and chemokine receptors in the homing pathway of HSV-2-specific effector cells from nasal to reproductive mucosa.

Previous studies have investigated the involvement of chemokine signaling in the retention of memory $\mathrm{T}$ cells in the genital tract. $^{13,14,36}$ After HSV-2 genital infection, IFN- $\gamma$-secreting CD4 ${ }^{+}$ $\mathrm{T}$ cells induce the expression of CXCL9 and CXCL10, which mediate the recruitment of $\mathrm{CD}^{+}$cytotoxic T lymphocytes (CTLs) through CXCR3 receptor signaling. ${ }^{36}$ Applying this information, researchers proposed a novel vaccination strategy in which circulating memory $\mathrm{CD}^{+} \mathrm{T}$ cells induced by systemic immunization with HSV-2 $\mathrm{TK}^{-}$might be recruited to-and retained in-the vaginal mucosa by topical treatment with CXCL9 and CXCL10. ${ }^{13}$ In addition, another recent and separate report showed that memory lymphocyte clusters in vaginal tissue, which are generated through intravaginal immunization with HSV-2 $\mathrm{TK}^{-}$, are maintained by CCL5 secreted from local macrophages. ${ }^{14}$ The findings from these studies imply that the interaction between the chemokine CCL5 and its receptor is important for maintaining tissue-resident memory $\mathrm{T}$ cells after intravaginal immunization with HSV-2. However, how this chemokine mediates the migration and retention of nasally primed effector T cells in genital tissue after nasal immunization was unclear.

In the present study, we delineated the chemokine receptor expressions on $\mathrm{CD}^{+}{ }^{+} \mathrm{T}$ cells after nasal immunization, because $\mathrm{CD}^{+} \mathrm{T}$ cells are a major source of local IFN $-\gamma$ production against viral infection; ${ }^{36,37}$ in addition, $\mathrm{CD}^{+}{ }^{+} \mathrm{T}$ cells support B-cell and $\mathrm{CD}^{+} \mathrm{CTL}$ responses by mobilizing CTLs into infected genital mucosa. ${ }^{36,38}$ Furthermore, a previous study showed that $\mathrm{CD}^{+}$ $\mathrm{T}$ cells-but not $\mathrm{CD}^{+}{ }^{+} \mathrm{T}$ cells or NK cells-are critical for the induction of protective immunity against challenge with WT HSV-2 in mice nasally immunized with HSV-2 $\mathrm{TK}^{-}{ }^{12}$ In the current study, we found that expression levels of both CCR5 and CXCR3 were upregulated in $\mathrm{CD}^{+}{ }^{+} \mathrm{T}$ cells after nasal immunization with HSV-2 
a

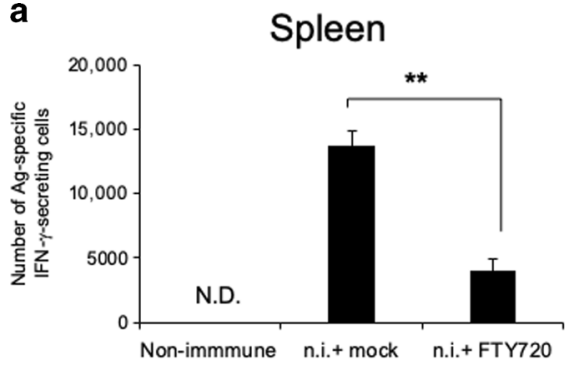

Vagina

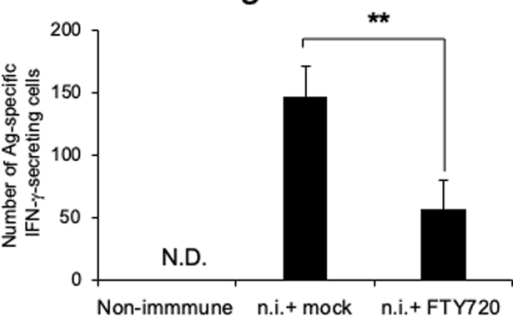

b

n.i. (Day 3)

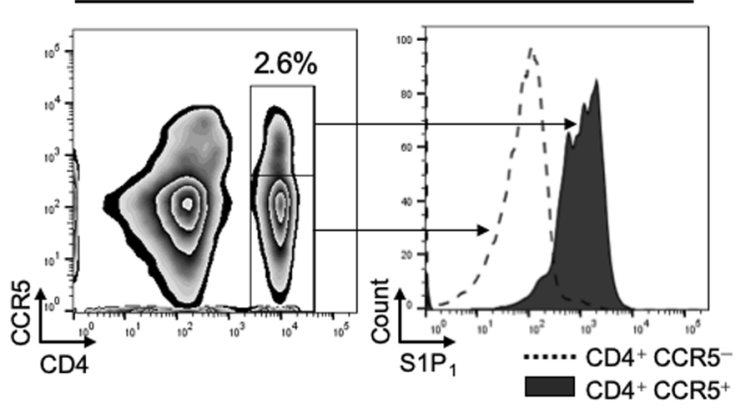

C
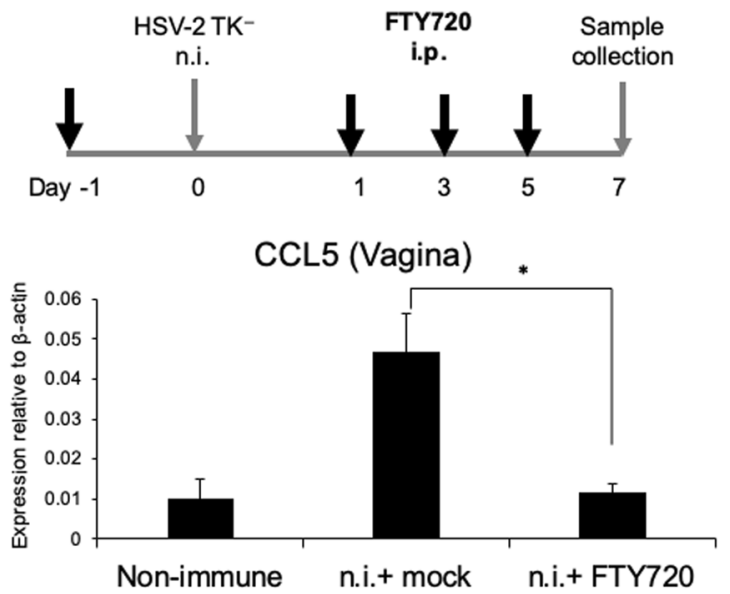

d
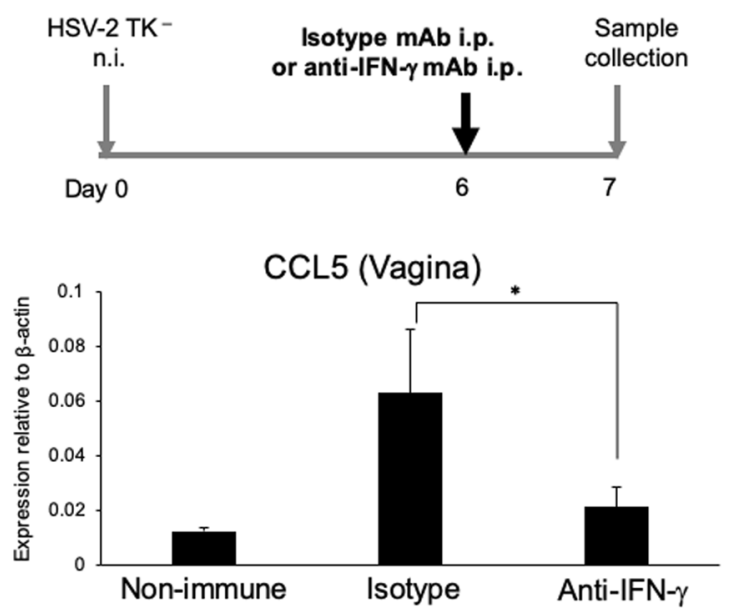

TK $^{-}$(Fig. 2b, Supplementary Fig. S1a). In this regard, others have showed that CXCL9 and CXCL10, ligands for CXCR3 production in vaginal mucosa, play key roles for the recruitment of effector $\mathrm{T}$ cells, including $\mathrm{CD}^{+}{ }^{+}$cells. $^{13}$ However, the same study reported that effector $\mathrm{CD}^{+} \mathrm{T}$ cells failed to remain in the vagina for a prolonged time. ${ }^{13}$ Indeed, our study likewise showed that deficiency of CCR5, but not of CXCR3, led to decreased retention of Ag-specific effector cells that had migrated from the nasal 
Fig. 6 The effects of FTY 720 treatment and blocking of IFN- $\gamma$. a Mice were injected intraperitoneally (i.p.) with FTY 720 (1 mg/kg/dose) or PBS (mock) every other day beginning 1 day before nasal immunization with HSV-2 $\mathrm{TK}^{-}$. At 1 week after immunization, the number of HSV-2specific IFN- $\gamma$-producing cells in spleen or vagina was assessed by ELISPOT assays. Data are the representative of two independent experiments $\left(n=3\right.$ or 4 mice per group). ${ }^{* *} P<0.01$. N.S. not significant. b Female mice were given a single nasal inoculation of PBS as nonimmunized control or $10^{5} \mathrm{PFU}$ of live HSV-2 $\mathrm{TK}^{-}$. Mononuclear cells were isolated from CLNs 3 days after immunization and were then stained for surface CD4, CCR5, and S1P 1 molecules. c Mice were treated i.p. with FTY 720 or PBS (mock) as described above. d Female C57BL/6 mice nasally immunized with $\mathrm{HSV}-2 \mathrm{TK}^{-}$on day 0 were treated with anti-IFN- $\gamma$ antibody or isotype antibody (both i.p.) on day 6 , and samples were collected on day 7. c, d RT-qPCR analysis of CCL5 expression in vaginal tissues. The CCL5 mRNA expression level was normalized to that of $\beta$-actin. Values are means \pm 1 SD $\left(n=4\right.$ mice per group). ${ }^{*} P<0.05$. Data are representative of three (b, c) or two (d) independent experiments

mucosa in mice nasally immunized with HSV-2 $\mathrm{TK}^{-}$(Fig. 2c, Supplementary Fig. S2). These findings clearly show an important role for CCR5 expression in the migration of IFN- $\gamma$-producing $\mathrm{CD}^{+}$ T cells into vaginal mucosa.

Because both $B$ cells and dendritic cells have been shown to upregulate Th1-type memory responses to $\mathrm{HSV}^{32}$ it is important to investigate potential roles of chemokine receptors for the migration of these cells into vagina tissue. However, given that our main focus in the current study was to define the cellular and molecular mechanisms of $\mathrm{CD}^{+}{ }^{+} \mathrm{T}$-cell migration from CLNs to vagina and their retention after nasal immunization with HSV-2 $\mathrm{TK}^{-}$, addressing this issue is beyond the scope of our current study. We plan to explore this issue in a separate and future investigation.

The chemokine ligands CCL3, CCL4, and CCL5 are reported to enhance Th1-type adaptive immunity through expression of Th1 cytokines (e.g., IFN- $\gamma$ ) and costimulatory molecules (e.g., CD28 and CD80). ${ }^{39,40}$ The present study showed that the expression levels of CCL3, CCL4, and CCL5 were remarkably upregulated in vaginal tissue after nasal immunization (Fig. 3a). However, in the chemokine-blocking experiment, only CCL5 blockade-but not CCL3 or CCL4 blockade-decreased the number of Ag-specific effector cells in the vagina after nasal immunization (Fig. 4a). This result suggests that CCL5 is the principal chemoattractant that serves to signal the migration of nasally primed effector cells to the vaginal mucosa. Several other lines of evidence show that CCL5 is the most potent chemokine for promoting leukocyte infiltration at sites of inflammation and for inducing immune responses to viral infection. ${ }^{39,41-43}$ In regard to STDs, CCL5 is necessary for protective mucosal immunity against Chlamydia, ${ }^{44}$ and CCL5 plays a key role in the immune response to infection by viruses such as HIV. ${ }^{42,45}$ Because CCL5 increases the proliferation and activation of antigen-stimulated $\mathrm{T}$ lymphocytes, ${ }^{39}$ it is plausible that CCL5 blockade in vaginal tissue might reduce the ability of immune cells to respond to immunization with HSV-2 $\mathrm{TK}^{-}$. Our current study clearly and directly demonstrates that among the three ligand chemokines for CCR5, CCL5 plays an indispensable role in the migration of $\mathrm{CCR5}^{+}$effector cells from the Ag-priming site of the nasal cavity and their migration to and subsequent retention in vaginal tissue (Fig. 4a, b).

To discern how nasal immunization with $\mathrm{HSV}-2 \mathrm{TK}^{-}$might induce CCL5 expression in distal genital tissue, we demonstrated that depletion of either lymphocyte migration or IFN- $\gamma$ secretion abrogates the induction of CCL5 in vaginal tissue by nasal immunization (Fig. 6). Previous studies have shown that Agspecific $T$ cells, but not Ag-loaded antigen-presenting cells, migrate from nasal tissues to distal lymph nodes after nasal immunization. ${ }^{12,46}$ Both $\mathrm{CD}^{+} 5^{+}$and $\mathrm{CD}^{-} 5^{-}$cells in vagina spontaneously produce higher levels of CCL5 when compared with those production in spleen (Fig. 3c). Given that the vast majority of $\mathrm{CCR5}^{+} \mathrm{CD}^{+}$T cells in CLNs induced by nasal HSV-2 $\mathrm{TK}^{-}$expressed sphingosine-1-phosphate receptor 1 ( $\mathrm{S}_{\mathrm{P}} \mathrm{P}_{1}$ ) (Fig. 6b), these cells immediately egress CLNs and preferentially migrate into vagina. We speculate that these are the initial steps of
CCR5-CCL5-dependent migration of effector $\mathrm{CD}^{+} \mathrm{T}$ cells. Of importance IFN- $\gamma$ produced by these CCR5 expressing $\mathrm{CD} 4^{+} \mathrm{T}$ cells contribute for the enhancement of CCL5 production by vaginal stromal cells (Supplementary Fig. S5). Taken together, our current data further support the concept that, after nasal immunization with HSV-2 $\mathrm{TK}^{-}$, nasally primed effector cells are recruited to vaginal tissue for Ag-specific secretion of IFN- $\gamma$. Then, the IFN- $\gamma$ generated locally amplifies the production of CCL5 in vaginal tissue, consequently leading to the robust recruitment of $\mathrm{Ag}$ specific effector cells from the systemic circulation to the female reproductive tract. The initial mechanism through which Agspecific effector cells are recruited to the vagina after nasal immunization warrants further investigation.

In the current study, mice that received CLN cells from nasally immunized $\mathrm{CCR}^{-/-}$mice were vulnerable to viral challenge and showed severe vaginal inflammation (Fig. 5). However, nasally immunized $\mathrm{CCR}^{-1-}$ mice survived viral challenge, demonstrating only mild clinical signs of infection and defects in early clearance of virus (Supplementary Fig. S4). In this regard, recent studies have suggested that tissue-resident memory T cells in genital mucosa are particularly important in establishing protective immunity against virus infection, because the responses of systemic circulating memory $T$ cells do not necessarily correlate with host protection. ${ }^{13,47}$ In addition, a study investigating nasal vaccination against Chlamydia trachomatis showed that optimal protection is initiated by tissue-resident memory $T$ cells (1st wave) and completed through recruitment of circulating memory $\mathrm{T}$ cells (2nd wave). ${ }^{48}$ Taking these findings into consideration, we speculate that nasally immunized $\mathrm{CCR}^{-/-}$mice survived but, unlike immunized WT mice, were unable to achieve optimal protection against high-titer viral challenge because $\mathrm{CCR}^{-1-}$ mice contained fewer but a moderate number of tissue-resident memory cells in vagina (Fig. 2c). Therefore, it is most likely that circulating memory T cells were recruited from peripheral blood to achieve the suboptimal protection.

In summary, we have demonstrated that selective chemokine and chemokine receptor signaling interactions are required for the migration of nasally primed effector cells from the nasal mucosa to the vagina. The current data showed that nasal immunization with HSV-2 $\mathrm{TK}^{-}$upregulates $\mathrm{CCR}^{+}$expression on $\mathrm{CD}^{+}{ }^{+} \mathrm{T}$ cells in antigen-priming sites (e.g., CLNs) and vaginal tissue. We have thus identified that the expression of chemokine CCL5 is upregulated in the vaginal tissue after nasal vaccination with $\mathrm{HSV}-2 \mathrm{TK}^{-}$and that intravaginal blockade of CCL5 diminished the number of HSV2 -specific effector cells in the vagina. The induction of CCL5 in vaginal tissue is largely dependent on IFN- $\gamma$-producing cells that migrated from secondary lymph nodes (e.g., CLNs). Furthermore, loss of CCR5, a receptor of CCL5, impairs the migration of nasally primed Ag-specific effector cells from nasal mucosa to the vagina. These results suggest that the CCR5-CCL5 axis promotes the homing of Ag-specific effector cells to the vaginal mucosa after nasal vaccination with HSV-2 $\mathrm{TK}^{-}$(Supplementary Fig. S6). The present findings highlight the importance of new strategies that activate the reproductive-specific homing pathway in the design of nasal vaccines against STDs. 


\section{MATERIAL AND METHODS}

Mice

Female 6- to 8-week-old C57BL/6JNcr (C57BL/6) mice were purchased from Japan SLC (Shizuoka, Japan). CCR5 ${ }^{-/-}$and $\mathrm{CXCR3}^{-/-}$mice were kindly provided by Dr. Kouji Matsushima (Graduate School of Medicine, University of Tokyo, Japan). Col GFP transgenic mice were provided by Dr. Yutaka Inagaki (Tokai University, Japan). All mice were maintained in the experimental animal facility at the Institute of Medical Science, University of Tokyo. All experiments were conducted in accordance with the guidelines provided by the Animal Care and Use Committees of the University of Tokyo and were approved by the Animal Committee of the Institute of Medical Science of The University of Tokyo.

Virus

Virulent HSV-2 strain 186syn ${ }^{+}$(WT HSV-2) and its thymidine kinase mutant, 186TK $\triangle \mathrm{Kpn}$ (HSV-2 $\mathrm{TK}^{-}$), were kindly provided by Prof. David Knipe (Harvard Medical School, Boston, MA). ${ }^{10}$ HSV-2 was propagated and titered on Vero cells (ATCC CCL-81) as previously described. ${ }^{49}$

\section{Immunization}

Female mice were immunized with a single nasal or intraperitoneal (i.p.) dose of $10^{5}$ PFU of live attenuated HSV-2 $\mathrm{TK}^{-}$(or nasal PBS for nonimmunized controls) ${ }^{12}$. For nasal immunization, isoflurane- (Nakalai Tesque, Kyoto, Japan) anesthetized mice were inoculated by instillation of $5 \mu \mathrm{l}$ of virus suspension into each nostril. ${ }^{12}$

For the "prime-and-pull" experiment, as described previously, ${ }^{13}$ mice were immunized subcutaneously with $10^{5} \mathrm{PFU}$ of HSV-2 $\mathrm{TK}^{-}$. At 6 days after immunization, mice received $10 \mu$ of PBS with or without $5 \mu \mathrm{g}$ of recombinant mouse CCL5 (R\&D Systems, Minneapolis, MN); these solutions were delivered into the vagina by using a pipette tip.

\section{Viral challenge}

By using a previously described protocol, ${ }^{12}$ mice were challenged intravaginally with $5 \times 10^{4}$ PFU (80 times the $50 \%$ lethal dose $\left.\left[\mathrm{LD}_{50}\right]\right)$ of HSV-2 $186 \mathrm{syn}^{+}$at 3 weeks after immunization. Briefly, the mice received a subcutaneous injection of $2 \mathrm{mg}$ of medroxyprogesterone acetate (Depo Provera, GE Healthcare, Tokyo, Japan) 1 week before challenge to increase their susceptibility to HSV-2 infection. ${ }^{50}$ The mice were then swabbed with a sterile calcium alginate swab (Fisher Scientific, Pittsburgh, PA) to remove mucus in the vaginal cavity and inoculated with $10 \mu \mathrm{l}$ of virus suspension into the vaginal lumen by micropipette. Disease severity was scored according to the previously described clinicalscoring method ${ }^{12}$ and as follows (5): 0, no signs; 1, slight genital erythema and edema; 2, moderate genital inflammation; 3, purulent genital lesions; 4, hindlimb paralysis; and 5, moribund.

\section{Cell preparation and flow cytometric analysis}

Mononuclear cells from spleen and CLNs were isolated aseptically by mechanical dissociation through stainless steel screens. Total lymphocytes from vagina tissue were prepared by tissue digestion with $1 \mathrm{mg} / \mathrm{ml}$ collagenase (Wako, Tokyo, Japan) and $30 \mu \mathrm{g} / \mathrm{mL}$ DNAse I (Sigma-Aldrich, St. Louis, MO) at $37^{\circ} \mathrm{C}$ for $30 \mathrm{~min} .{ }^{12}$ The resulting cells were filtered through a $70-\mu \mathrm{m}$ filter. In some experiments, stromal cells were isolated from vaginal tissue of ColGFP transgenic mice and sorted by flow cytometry (FACSAria II, BD Biosciences, San Jose, CA). Purified vaginal stromal cells $\left(1 \times 10^{5} /\right.$ $\mathrm{ml})$ were incubated with recombinant IFN- $\gamma(10 \mu \mathrm{g} / \mathrm{ml}, \mathrm{R} \& D$ Systems) for 3 days.

Isolated cells were incubated with $5 \mu \mathrm{g} / \mathrm{ml}$ of anti-CD16/32 (anti-FcyRII/III) Ab for $5 \mathrm{~min}$ and then stained for $30 \mathrm{~min}$ at $4{ }^{\circ} \mathrm{C}$ with fluorescence-labeled monoclonal antibodies (mAbs). Fluorescent mAbs specific for anti-CD3ع (145-2C11), anti-CD4 (RM4-5),
anti-CCR5 (C34-3448), anti-CXCR4 (2B11), anti-IFN-y (XMG1.2) (all from BD Pharmingen, Franklin Lakes, NJ), anti-CXCR3 (CXCR3-173; e-Bioscience, San Diego, CA), anti-CD4 (GK1.5), anti-CD8a (53-6.7), anti-CD44 (IM7), anti-CD45 (30-F11), anti-CD49a (HMa1), CD69 (H1.2F3) (all from BioLegend, San Diego, CA), or anti-S1P1 (713412, R\&D Systems) were used. Flow cytometric analysis was performed and analyzed by using the FACS Calibur and FACS Canto II systems (BD Biosciences).

Cell isolation by magnetic activated cell sorting

To isolate $\mathrm{CD}_{4} 5^{+}$cells, mononuclear cells were obtained from vaginal tissues as described above section. Both $\mathrm{CD}_{4} 5^{-}$and $\mathrm{CD}^{+} 5^{+}$cells were enriched by using anti-CD45-labeled MicroBeads (Miltenyi Biotec, Auburn, CA) according to the manufacturer's instructions. The purity of the positively selected cells was $\sim 85 \%$. Both $\mathrm{CD} 45^{-}$and $\mathrm{CD} 45^{+}$cells subsequently underwent mRNA analysis.

\section{Ag-specific IFN- $\gamma$ ELISPOT assay}

For Ag-specific IFN- $\gamma$ ELISPOT assays, mice were euthanized 1 week after immunization. Total lymphocytes from vagina or spleen were prepared as described earlier. Lymphocytes were stimulated for $72 \mathrm{~h}$ in vitro with irradiated syngeneic splenocytes as Ag-presenting cells in the presence of mock or heat-inactivated HSV-2 TK $^{-}$Ag, as previously described. ${ }^{49}$ Stimulated cells were analyzed for IFN- $\gamma$ production by ELISPOT assay in accordance with the manufacturer's instructions (e-Bioscience and BD Biosciences, Oxford, United Kingdom). The number of HSV-2 specific ISCs per tissue was calculated by subtracting the number of ISCs in wells absent of HSV-2 Ag from the number of ISCs in wells stimulated with $\mathrm{HSV}-2 \mathrm{Ag}$ and were quantified by using ZEISS KS ELISPOT software (Oberkochen, Germany).

\section{RNA quantification}

Total RNA was prepared from mouse tissues or vaginal stromal cells by using TRIzol reagent (Invitrogen, Carlsbad, CA), and then cDNA was synthesized by using PrimeScript RT Master Mix (Takara, Shiga, Japan) according to the manufacturer's protocol. The cDNA underwent by RT-qPCR analysis by using Fast SYBR Green Master Mix and the Step One Plus Real-Time PCR System (Applied Biosystems, Carlsbad, CA, USA). Expression levels were normalized to that of $\beta$-actin. The PCR primers used are listed in Supplementary Table 1.

\section{Immunohistochemistry}

Vaginal tissue samples from immunized WT mice or col-GFP transgenic mice were fixed in $4 \%$ paraformaldehyde (Nakalai Tesque) and then treated with a sucrose gradient (10-30\%). The tissue was embedded in Tissue-Tek compound (Sakura Finetek, Tokyo, Japan) and cut into 7- $\mu$ m-thick sections. The sections were stained with 4,6-diamidino-2-phenylindole (Invitrogen), antimouse CCL5 Ab (R\&D Systems), and biotinylated anti-CD45 mAb (BD Biosciences), after which the signal was detected and quantitated by using the tyramide signal amplification system (PerkinElmer) according to the manufacturer's instructions. All samples were mounted and then analyzed by DMIRE2 TCS SP2 confocal microscopy (Leica, Wetzlar, Germany). The merged-color (i.e., yellow) cells in the staining image were counted or the intensity of yellow color pixels in a selected region of the stained image was quantified by using ImageJ software (National Institutes of Health, Bethesda, MD).

In vivo treatment with PTx and neutralizing Abs

Female C57BL/ 6 mice immunized with $10^{5} \mathrm{PFU}$ of live attenuated HSV-2 TK $^{-}$were treated intravaginally with $0.5 \mu \mathrm{g}$ of PTx (SigmaAldrich) for 4 consecutive days (i.e., days 3 through 6) after nasal immunization. On day 7, mice were euthanized for Ag-specific IFNY ELISPOT assay as described earlier. 
For chemokine ligand-blocking experiments, female C57BL/6 mice nasally immunized with $\mathrm{HSV}-2 \mathrm{TK}^{-}$were treated with antimouse CCL3 or CCL4 or CCL5 mAb (all from R\&D Systems; $1 \mu \mathrm{g}$ per vagina) or a cocktail of Abs (mixture of anti-CCL3 Ab, anti-CCL4 Ab, and anti-CCL5 Ab) intravaginally for 4 consecutive days (days 3 through 6) after immunization. ${ }^{14}$ On day 7 , mice were euthanized for Ag-specific IFN- $\gamma$ ELISPOT assays as described earlier.

For IFN- $\gamma$ depletion, nasally immunized mice were injected intraperitoneally with $500 \mu \mathrm{g}$ of neutralizing mAb against IFN- $\gamma$ (XMG1.2, BioXcell, West Lebanon, NH) or rat IgG1 isotype control mAb (R\&D Systems) on day 6 after immunization. ${ }^{36}$

To block T-cell egress from secondary lymph nodes, mice were injected intraperitoneally with FTY $720(1 \mathrm{mg} / \mathrm{kg}$ bodyweight per dose; Sigma-Aldrich) 1 day before immunization and then every other day thereafter until harvest. ${ }^{31}$

\section{Adoptive transfer and infection experiment}

For adoptive transfer, whole cells from CLNs of WT C57BL/6 mice or $\mathrm{CCR5}^{-1-}$ mice that had been nasally immunized with HSV-2 $\mathrm{TK}^{-} 7$ days earlier were prepared as described above. The cells $\left(10^{7}\right.$ cells) were then adoptively transferred retro-orbitally into WT, unimmunized C57BL/6 recipients, which had been pretreated with Depo-Provera (GE Healthcare), as previously described. ${ }^{13}$ Two hours later, the mice were infected intravaginally with WT HSV-2 virus $\left(5 \times 10^{4} \mathrm{PFU}, 80\right.$ times the $\left.\mathrm{LD}_{50}\right)$ and monitored for clinical signs, as described earlier.

Viral titration in vaginal washes

Vaginal washes were collected on days 1-5 after infection by swabbing with calcium alginate swabs and then washing twice with $100 \mu$ l of sterile PBS. ${ }^{12}$

Viral titers were obtained by titration of vaginal-wash samples on Vero cell monolayers, as described previously. ${ }^{49,50}$ After plating Vero cells on 12-well plate, tenfold serial dilutions of the vaginalwash samples were added to wells and the plate was incubated for $48 \mathrm{~h}$ at $37^{\circ} \mathrm{C}$ in $5 \% \mathrm{CO}_{2}$. After incubation, Vero cells were fixed with methanol (Nakalai Tesque) and stained with $1 \%$ crystal violet; plaques (PFU) were counted and multiplied by the dilution factor of the vaginal-wash sample to obtain the viral titer.

\section{DATA ANALYSIS}

Data are expressed as means \pm 1 standard deviation (SD) or the standard error of the mean. Statistical analysis for comparisons among groups was performed by using either a two-tailed Student's $t$ test or one-way ANOVA test. $P$ values less than 0.05 were considered significant.

\section{ACKNOWLEDGEMENTS}

We would like to thank Prof. David Knipe (Harvard Medical School, Boston, MA) for kindly providing HSV-2 strain 186syn + and $186 \mathrm{TK}^{-}$and Prof. Yutaka Inagaki (Tokai University, Japan) for providing Col-GFP transgenic mice. This work was supported by grants from the Ministry of Education, Culture, Sports, Science, and Technology of Japan [Grant-in-Aid for Scientific Research S (23229004)], the Core Research for Evolutional Science and Technology Program of the Japan Science, and a Technology Agency and Health Labor Sciences Research Grant from the Ministry of Health, Labor and Welfare of Japan.

\section{AUTHOR CONTRIBUTIONS}

Conceived and designed the experiments: S.J., A.S., A.Sa., R.N.O., K.F., H.K. Performed the experiments: S.J., A.S., R.N.O., H.M., Y.U. Analyzed the data: S.J., A.S., A.Sa., S.S., R.N. O., Y.Ku., Y.Y., K.F., Y.K., H.K. Contributed reagents/materials/analysis tools: A.Sa., S.S., Y. K. Wrote the paper: S.J., A.S., R.N.O., Y.Y., K.F., H.K. Performed and managed various experiments: A.Sa., S.S., Y.K.

\section{ADDITIONAL INFORMATION}

The online version of this article (https://doi.org/10.1038/s41385-019-0203-z) contains supplementary material, which is available to authorized users.

Competing interest: The authors declare no competing interests.

Publisher's note Springer Nature remains neutral with regard to jurisdictional claims in published maps and institutional affiliations.

\section{REFERENCES}

1. Iwasaki, A. Antiviral immune responses in the genital tract: clues for vaccines. Nat. Rev. Immunol. 10, 699-711 (2010).

2. Dropulic, L. K. \& Cohen, J. I. The challenge of developing a herpes simplex virus 2 vaccine. Expert Rev. Vaccines 11, 1429-1440 (2012).

3. Looker, K. J. et al. Global estimates of prevalent and incident herpes simplex virus type 2 infections in 2012. PLOS ONE 10, e114989 (2015).

4. Cohen, J. Immunology. Painful failure of promising genital herpes vaccine. Science 330, 304 (2010).

5. Belshe, R. B. et al. Efficacy results of a trial of a herpes simplex vaccine. N. Engl. J. Med. 366, 34-43 (2012).

6. Roth, K., Ferreira, V. H. \& Kaushic, C. HSV-2 vaccine: current state and insights into development of a vaccine that targets genital mucosal protection. Microb. Pathog. 58, 45-54 (2013).

7. Holmgren, J. \& Czerkinsky, C. Mucosal immunity and vaccines. Nat. Med. 11(4 Suppl), S45-S53 (2005).

8. Fujkuyama, Y. et al. Novel vaccine development strategies for inducing mucosal immunity. Expert Rev. Vaccines 11, 367-379 (2012).

9. Riese, P., Sakthivel, P., Trittel, S. \& Guzman, C. A. Intranasal formulations: promising strategy to deliver vaccines. Expert Opin. Drug Deliv. 11, 1619-1634 (2014).

10. Coen, D. M. et al. Thymidine kinase-negative herpes simplex virus mutants establish latency in mouse trigeminal ganglia but do not reactivate. Proc. Natl Acad. Sci. USA 86, 4736-4740 (1989).

11. Milligan, G. N., Dudley-McClain, K. L., Chu, C. F. \& Young, C. G. Efficacy of genital T cell responses to herpes simplex virus type 2 resulting from immunization of the nasal mucosa. Virology 318, 507-515 (2004).

12. Sato, A. et al. Vaginal memory $T$ cells induced by intranasal vaccination are critical for protective T cell recruitment and prevention of genital HSV-2 disease. J. Virol. 88, 13699-13708 (2014)

13. Shin, H. \& Iwasaki, A. A vaccine strategy that protects against genital herpes by establishing local memory T cells. Nature 491, 463-467 (2012).

14. lijima, N. \& Iwasaki, A. T cell memory. A local macrophage chemokine network sustains protective tissue-resident memory CD4 T cells. Science 346, 93-98 (2014).

15. Parr, M. B. et al. A mouse model for studies of mucosal immunity to vaginal infection by herpes simplex virus type 2. Lab. Investig. 70, 369-380 (1994).

16. Gallichan, W. S. \& Rosenthal, K. L. Long-lived cytotoxic T lymphocyte memory in mucosal tissues after mucosal but not systemic immunization. J. Exp. Med. 184, 1879-1890 (1996).

17. Shin, H. \& Iwasaki, A. Tissue-resident memory T cells. Immunol. Rev. 255, 165-181 (2013).

18. Sigmundsdottir, H. \& Butcher, E. C. Environmental cues, dendritic cells and the programming of tissue-selective lymphocyte trafficking. Nat. Immunol. 9, 981-987 (2008)

19. lijima, N. \& Iwasaki, A. Tissue instruction for migration and retention of TRM cells. Trends Immunol. 36, 556-564 (2015).

20. Moser, B. \& Loetscher, P. Lymphocyte traffic control by chemokines. Nat. Immunol. 2, 123-128 (2001).

21. Zlotnik, A. \& Yoshie, O. Chemokines: a new classification system and their role in immunity. Immunity 12, 121-127 (2000).

22. Fuhlbrigge, R. C., Kieffer, J. D., Armerding, D. \& Kupper, T. S. Cutaneous lymphocyte antigen is a specialized form of PSGL-1 expressed on skin-homing T cells. Nature 389, 978-981 (1997).

23. Campbell, J. J. et al. The chemokine receptor CCR4 in vascular recognition by cutaneous but not intestinal memory T cells. Nature 400, 776-780 (1999).

24. Kunkel, E. J. et al. Lymphocyte CC chemokine receptor 9 and epithelial thymusexpressed chemokine (TECK) expression distinguish the small intestinal immune compartment: epithelial expression of tissue-specific chemokines as an organizing principle in regional immunity. J. Exp. Med. 192, 761-768 (2000).

25. Zabel, B. A. et al. Human G protein-coupled receptor GPR-9-6/CC chemokine receptor 9 is selectively expressed on intestinal homing $T$ lymphocytes, mucosal lymphocytes, and thymocytes and is required for thymus-expressed chemokinemediated chemotaxis. J. Exp. Med. 190, 1241-1256 (1999). 
26. lijima, N. \& Iwasaki, A. Access of protective antiviral antibody to neuronal tissues requires CD4 T-cell help. Nature 533, 552-556 (2016).

27. Kunkel, E. J. \& Butcher, E. C. Chemokines and the tissue-specific migration of lymphocytes. Immunity 16, 1-4 (2002).

28. McKinney-Freeman, S. L. et al. Surface antigen phenotypes of hematopoietic stem cells from embryos and murine embryonic stem cells. Blood 114, 268-278 (2009).

29. Yata, Y. et al. DNase I-hypersensitive sites enhance a1(I) collagen gene expression in hepatic stellate cells. Hepatology 37, 267-276 (2003).

30. Cyster, J. G. Chemokines, sphingosine-1-phosphate, and cell migration in secondary lymphoid organs. Annu Rev. Immunol. 23, 127-159 (2005).

31. Cha, H. R. et al. Mucosa-associated epithelial chemokine/CCL28 expression in the uterus attracts $\mathrm{CCR}^{+} 0^{+} \mathrm{IgA}$ plasma cells following mucosal vaccination via estrogen control. J. Immunol. 187, 3044-3052 (2011).

32. lijima, N. et al. Dendritic cells and B cells maximize mucosal Th1 memory response to herpes simplex virus. J. Exp. Med. 205, 3041-3052 (2008).

33. Harandi, A. M., Svennerholm, B., Holmgren, J. \& Eriksson, K. Differential roles of B cells and IFN- $\gamma$-secreting $\mathrm{CD}^{+}{ }^{+} \mathrm{T}$ cells in innate and adaptive immune control of genital herpes simplex virus type 2 infection in mice. J. Gen. Virol. 82(Pt 4), 845-853 (2001)

34. Huston, W. M., Harvie, M., Mittal, A., Timms, P. \& Beagley, K. W. Vaccination to protect against infection of the female reproductive tract. Expert Rev. Clin. Immunol. 8, 81-94 (2012).

35. Parr, E. L. \& Parr, M. B. Immune responses and protection against vaginal infection after nasal or vaginal immunization with attenuated herpes simplex virus type- 2 . Immunology 98, 639-645 (1999).

36. Nakanishi, Y., Lu, B., Gerard, C. \& Iwasaki, A. CD8 ${ }^{+}$T lymphocyte mobilization to virus-infected tissue requires $\mathrm{CD}^{+}{ }^{+}$T-cell help. Nature 462, 510-513 (2009).

37. Shin, H. \& Iwasaki, A. Generating protective immunity against genital herpes. Trends Immunol. 34, 487-494 (2013).

38. Swain, S. L., McKinstry, K. K. \& Strutt, T. M. Expanding roles for CD4 ${ }^{+}$T cells in immunity to viruses. Nat. Rev. Immunol. 12, 136-148 (2012).
39. Lillard, J. W. Jr., Boyaka, P. N., Taub, D. D. \& McGhee, J. R. RANTES potentiates antigen-specific mucosal immune responses. J. Immunol. 166, 162-169 (2001).

40. Lillard, J. W. Jr. et al. MIP-1a and MIP-1 $\beta$ differentially mediate mucosal and systemic adaptive immunity. Blood 101, 807-814 (2003).

41. Appay, V. \& Rowland-Jones, S. L. RANTES: a versatile and controversial chemokine. Trends Immunol. 22, 83-87 (2001).

42. Hadida, F. et al. HIV-specific T cell cytotoxicity mediated by RANTES via the chemokine receptor CCR3. J. Exp. Med. 188, 609-614 (1998).

43. Melchjorsen, J., Sorensen, L. N. \& Paludan, S. R. Expression and function of chemokines during viral infections: from molecular mechanisms to in vivo function. J. Leukoc. Biol. 74, 331-343 (2003).

44. Sakthivel, S. K. et al. CCL5 regulation of mucosal chlamydial immunity and infection. BMC Microbiol. 8, 136 (2008).

45. Wagner, L. et al. $\beta$-chemokines are released from HIV-1-specific cytolytic T-cell granules complexed to proteoglycans. Nature 391, 908-911 (1998).

46. Ciabattini, A. et al. Distribution of primed T cells and antigen-loaded antigen presenting cells following intranasal immunization in mice. PLOS ONE 6, e19346 (2011).

47. Gebhardt, T. et al. Memory T cells in nonlymphoid tissue that provide enhanced local immunity during infection with herpes simplex virus. Nat. Immunol. 10, 524-530 (2009).

48. Stary, G. et al. A mucosal vaccine against Chlamydia trachomatis generates two waves of protective memory T cells. Science 348, aaa8205 (2015).

49. Zhao, X. et al. Vaginal submucosal dendritic cells, but not Langerhans cells, induce protective Th1 responses to herpes simplex virus-2. J. Exp. Med. 197, 153-162 (2003).

50. Gillgrass, A. E., Ashkar, A. A., Rosenthal, K. L. \& Kaushic, C. Prolonged exposure to progesterone prevents induction of protective mucosal responses following intravaginal immunization with attenuated herpes simplex virus type 2 . J. Virol. 77, 9845-9851 (2003). 